\title{
DSS for Agricultural Products Supply Chain Risk Balancing using Stakeholder Dialogues and Fuzzy Non Linear Regression
}

\author{
Suharjito $^{1}$ and Marimin ${ }^{2}$ \\ ${ }^{1}$ Magister of Information Technology, Bina Nusantara University, Jakarta, \\ Indonesia \\ ${ }^{2}$ Faculty of Agricultural Technology, Bogor Agricultural University, Bogor, \\ Indonesia. \\ suharjito@binus.edu
}

\begin{abstract}
The high complexity of the supply chain network and the characteristics of products made supply chain management of agricultural products were more susceptible to the risks emergence of loss. Therefore, it is required to develop a mechanism for price negotiation which distributes the risks fairly for each stakeholder in the supply chain. In addition it is necessary to identify and evaluate supply chain risks in order to avoid continuing problems that can occur at any point in the supply chain network. The objectives of this study were to describe the model of identification and evaluation for corn supply chain risk, to formulate a fair pricing mechanism for corn supply chain using risk balancing model. Risk identification was conducted using fuzzy Analytical Hierarchy Process (AHP) approach and risk evaluation was done by using fuzzy logic with data input form the opinion of several experts maize supply chain. A fairly pricing model at farmer level was developed by using stakeholder dialogue approach based on a balanced fuzzy risk utility preference that was faced by all stages of the supply chain. In addition, fuzzy risk utility optimization was used to get a consensus of the supply chain stakeholder dialogue, where basic risk utility function was derived using fuzzy regression approach. Risk mitigation for each stage of supply chain was developed using fuzzy inferences based on the risk that has been evaluated. Based on the verification results, the model could identify the level of risks for each party of the supply chain and the action that must be taken for minimizing its impacts using appropriate strategies. The model could shift the risks from the farmer to the other parties to determine the fair benefit distribution on the price negotiation.
\end{abstract}

Keywords: supply chain, risk balancing, fuzzy utility, optimization, stakeholder dialogue

\section{Introduction}

Risk management of supply chain is different form general risk management, becouse of those special characteristics of supply chain risk, it still has some aspects needed to be paid attention to, such as complex interactions within numerous business partners, which is the main reason why supply chain risks are more difficult to identify and manage [12]. There are many types of risks faced by the supply chain such as risks resulting from: demand problems, problems in fulfilling customer deliveries, cost management and pricing, and weaknesses in resources, development and flexibility, so it requires joint effort to mitigate them [8].

Coordination is essential key for successful supply chain management. There are some papers that explain coordination in supply chain throught negotiation for thier conflict of objectives such as Jain and Deshmukh [11] develops a hybrid negotiation based mechanism for supply chain management, that combines both cooperative and 
competitive negotiations using fuzzy logic approach on multi agent system. Yang and Chiang [30] explores the performance of revenue-sharing contracts under explicit consideration of risk-averse members of the supply chain. Moon, Yao, and Park [13] examined formal bilateral negotiation in a supply contract where the buyer's revenue and the seller's cost are uncertain, and discussed the roles of the uncertainty in negotiation outcomes for pricing. There are few of research on the design of a framework for collaborative risk management and various possible schemes for collaborative risk management between organizations in a supply chain, since supply chain risk management is still in the infancy stage and the need for better supply chain risk management is high [24]. Therefore it can be developed a mechanism to mitigate the risks of supply chain using collaborative and negotiation to get risk balancing in the supply chain network.

Consensus is a form of shared decision-making among multiple stakeholders who have a conflict of interest in achieving a goal [10]. Conflict resolution to make decisions together or group has been widely described by several studies [13], and [18]. While the used of stakeholder dialogue for conflict resolution has been presented by [5] and [25]. But a resolution of conflict in decision-making of supply chain risk management has not been done yet, based on some literaturs review, especially on Agricultural Products Supply Chain Management (AP-SCM).

In the AP-SCM, farmers as one of the perpetrators of the supply chain of agricultural products do not have enough bargaining power in price determination because agricultural products are perishable and seasonal, so the risk at farm level is higher than the risk at other levels in the supply chain network [21]. Therefore, there should be a mechanism to balance the risks faced by each level of the supply chain to improve their bargaining position at the farmer level. Improving their bargaining position is often done by consensus through stakeholder dialogue among supply chain actors. This paper described a mechanism for determining the price at farm level with fuzzy risk utility optimization approach to help geting a resolution of conflicts of interest in a systematic approach using stakeholder dialogue among supply chain actors.

Critical risk often faced by all stages of the AP-SCM is the risk of price fluctuations [1]. Therefore it is necessary to have a method to overcome this risk together so that it will be created a balance of risk among actors of the supply chain. One mechanism to obtain solutions for conflict resolution in balancing supply chain risk is stakeholder dialogue. Resolution in stakeholder dialogue is essential because in mitigating the risk of price fluctuation will arise various conflicts of interest in making a deal with the price.

This paper describes a pricing model of supply chain by using stakeholder dialoge based on risk balancing of each stage of supply chain. On the next section discusses some literature review that relates to pricing negotiation on supply chain and supply chain risk balancing using stakeholder dialog. In Section 3 a framework model to assist price negotiation outomaticaly on AP-SCM stakeholder dialoge based on thier risks constraint is presented. Section 4 discusses an application example of this model for developing supply chain stakeholder dialoge on balancing thier risks of price negotiation. Finnaly, Section 5 concludes some key points on implementing supply chain risk balancing model on AP-SCM.

\section{Literature Review}

Risk management in general is described as the identification and analysis of risks as well as their control. A main particularity of Supply Chain Risk Management (SCRM) contrary to traditional risk management is that it is characterized by a cross-company orientation aiming at the identification and reduction of risks not only on the company level, but rather focusing on entire supply chains. Risk identification is an important 
component in the risk analysis procedure [27]. Some clasification of risk in supply chain from literature review can be summary on Table 1 .

In this paper, we adopt the broad classification of risks by [14], [23], [19]. The existing studies that are found in the literature have been instrumental in identifying and analyze several causes of disruptions and risks in supply chains. However, it could not be found any literature that discusses risks identification on each stage of supply chain network. This paper will present this issues especially on AP-SCM.

Tabel 1. Supply Chain Risk Categories from Literature

\begin{tabular}{|c|c|}
\hline Reference & Supply chain risk categories and Risk variables/types \\
\hline $\begin{array}{l}\text { Oke \& } \\
\text { Gopalakrishnan } \\
{[14]}\end{array}$ & $\begin{array}{l}\text { - Supply risks (Imports risk, climate, man-made disaster, Natural disasters, Socio- } \\
\text { economic, Loss of key suppliers) } \\
\text { Demand Risks (Economic, Demand variability and uncertainty, Product hazards, } \\
\text { Outbreak, Fads, Ban on ingredients, Forecasting errors) } \\
\text { - Miscellaneous risks (Increasing gas prices, Global consumption, Regulations, } \\
\text { Ethical Treatment of Animals) }\end{array}$ \\
\hline $\begin{array}{c}\text { Tang \& } \\
\text { Tomlin [23] }\end{array}$ & $\begin{array}{ll}\text { - } & \text { Supply risks (Supply cost, supply quality \& Supply commitment risks) } \\
\text { - } & \text { Process risks (quality, time, and capacity risks for in-bound and out-bound } \\
\text { - } & \text { logistics risks) } \\
\text { - } & \text { Demand risks (unpredictable demand volume and demand mix) } \\
\text { - } & \text { contractual property risks (outsourcing, off- shoring, suppliers licensing or } \\
\text { - } & \begin{array}{l}\text { Behavioral risks (number of partner, low visibility and control level of } \\
\text { information) }\end{array} \\
\text { - } & \text { Political/social risks (political battles, unemployment) }\end{array}$ \\
\hline $\begin{array}{l}\text { Schoenherr, } \\
\text { Tummala, \& } \\
\text { Harrison [19] }\end{array}$ & $\begin{array}{l}\text { Product cost, Product quality, Order fulfillment risk, Transportation risk, ANSI } \\
\text { compliance, Competitor cost, Supplier fulfillment risk, On-time/on-budget delivery, } \\
\text { Logistics risk, Sovereign Risk, Wrong partner risk, Overseas risk, Supplier risk, } \\
\text { Demand Risk, Supplier's supplier management, Natural disasters/terrorism, } \\
\text { Engineering and innovation. }\end{array}$ \\
\hline $\begin{array}{l}\text { Xiaohui, } \\
\text { Xiaobing, Shiji, \& } \\
\text { Cheng [28] }\end{array}$ & 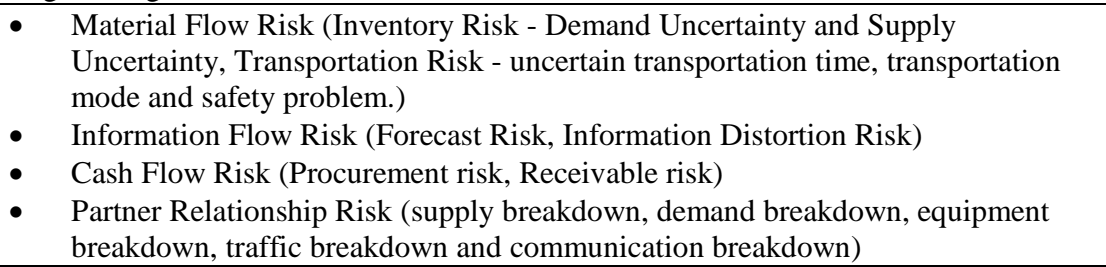 \\
\hline $\begin{array}{l}\text { Wu, } \\
\text { Blackhurst, \& } \\
\text { Chidambaram [27] }\end{array}$ & $\begin{array}{l}\text { In-bound supply risk (Cost, Quality, On-time delivery, Continuity of supply, } \\
\text { Engineering/production, second Tier supplier, Demand, Internal legal issues, } \\
\text { Natural/man-made disasters, Politics/economics, Others) }\end{array}$ \\
\hline Peck, [16] & $\begin{array}{l}\text { Risks exist at different levels-product/ process, assets, organizations and inter- } \\
\text { organizational networks, environment }\end{array}$ \\
\hline $\begin{array}{l}\text { Spekman \& } \\
\text { Davis [20] }\end{array}$ & $\begin{array}{l}\text { Supply risks, inventory, information flow, money flow, security, opportunistic } \\
\text { behavior, corporate social responsibility }\end{array}$ \\
\hline $\begin{array}{l}\text { Chopra \& } \\
\text { Sodhi [4] }\end{array}$ & $\begin{array}{l}\text { Major natural and man-made disasters, supply risks, systems, forecast, intellectual } \\
\text { property, inventory and capacity }\end{array}$ \\
\hline $\begin{array}{l}\text { Harland, } \\
\text { Brenchley, \& } \\
\text { Walker [9] }\end{array}$ & $\begin{array}{l}\text { Strategic Risk, Operations Risk, Supply Risk, Customer Risk, Asset Impairment Risk, } \\
\text { Competitive Risk, Reputation Risk, Financial Risk, Fiscal Risk, Regulatory Risk, Legal } \\
\text { Risk. }\end{array}$ \\
\hline
\end{tabular}

A tool of supply chain risk management has been proposed by Harland et al. [9]. This tool begins with mapping the supply network, then involves identifying risk and its current location, assessing that risk, managing the risk, forming a collaborative supply network risk strategy, and finally, implementing a supply network risk strategy. Detail steps of this tool can be found on Figure 1. 


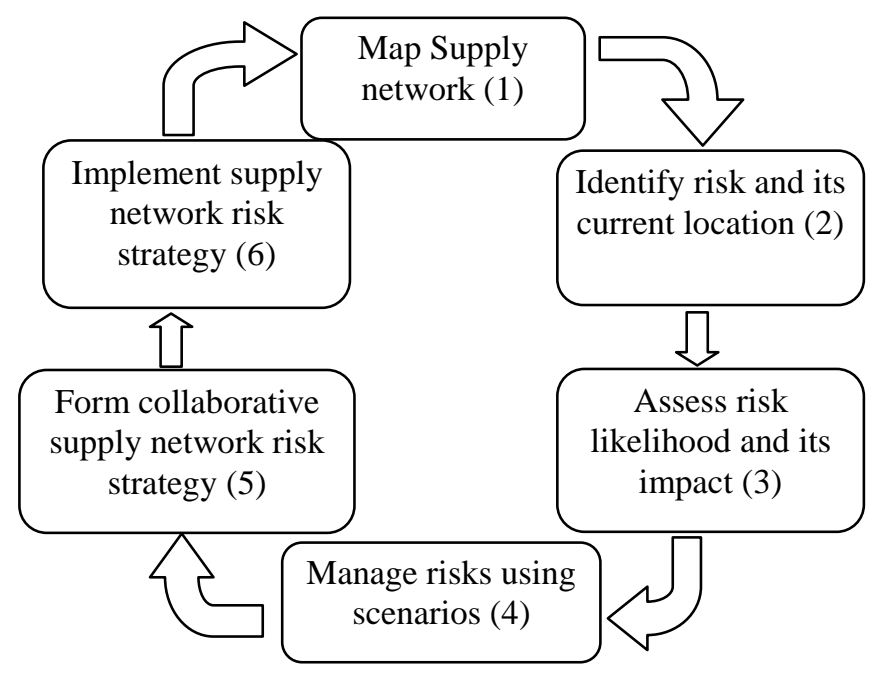

\section{Figure 1. Supply Network Risk Tool [9]}

From this tool can be found that one strategy for managing supply chain risk is forming a collaboration. To form a collaboration for each stakeholder of supply chain needs some mechanism to reduce some conflicts of interest. Stakeholder negotiation is ussualy used to generate a consensuss of a conflict. There are some researchs on developing negotiation. Moon et al,. [13] has examined formal bilateral negotiation in a supply contract where the buyer's revenue and the seller's cost are uncertain. A negotiation mechanism with fuzzy technology for automating B2B process has been presented by Rau, Chen, \& Chen [17]. The advantage of fuzzy logic and develops a hybrid negotiation-based mechanism, that combines both cooperative and competitive negotiations has been studied by Jain and Deshmukh [11]. Cheng, Chan, and Lin [3] has discussed automated negotiation on e-marketplace the user's utility function for autonomous intelligent agents. Most of the literature used bilateral negotiation mechanism, in this paper will be used a multilateral negotiation mechanism to balance the risks of $\mathrm{AP}-\mathrm{SCM}$ as represented in Figure 2.

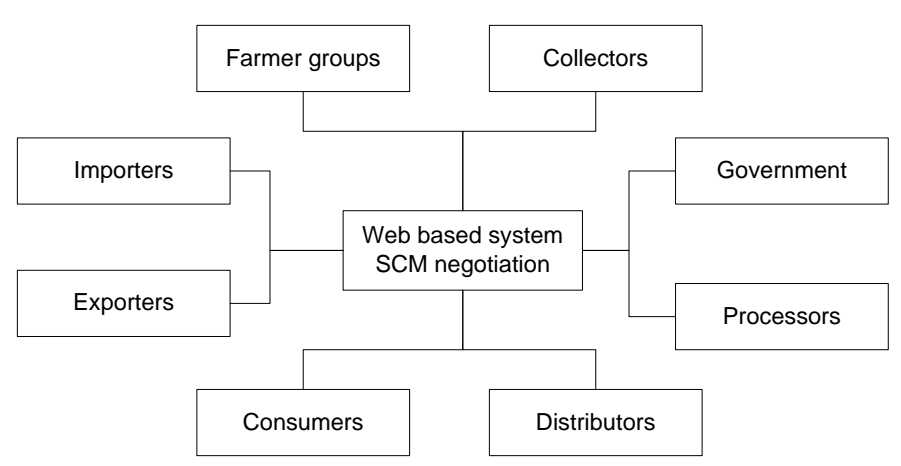

Figure 2. AP-SCM Stakeholders

In a broad sense, stakeholders can be considered as those individuals or groups that have an interest or concern in a particular issue. There are a variety of potential stakeholders who can be governmental or non-governmental, pursue their individual or group interests, act on local, national or global scales. Dialogues or interactive decisionmaking are an opportunity to bring the diversity of stakeholders together for the discussion or resolution of burning societal problems. Stakeholder dialogues empower the parties involved and seek to reconcile and integrate divergent interests to reach agreement 
or consensus. Cuppen et al. [5] uses stakeholder dialogues for assessing complex ecological and environmental problems. Welp et al. [25] presented science-based stakeholder dialogues to examine global change problems in the frameworks of sustainability science.

Utility is partiality feeling of policymaker or quantitative index of the response to the income or loss value made by consequence in risky cases. In many cases, a party's preferences can be mapped to values of utility, where higher utility means greater preference [26]. The use of utility theory for resolving conflict of interests between the parties to the dispute has been conducted by several studies. Tamura [22] constructed a two-attribute group disutility function for two conflicting decision makers on planning a safe, secure and reliable megacity. Yang and Qiu [29] developed a new measure of risk based on the expected utility and entropy to establish decision making model under risk. Ding, et al. [6] have proposed analytical model that incorporates two well-accepted behavioral regularities into a classic utility function: Consumers infer quality from price and make judgments relative to a reference price.

Conflict resolution to make decisions together or group has been widely described by several papers. But the resolution of conflict in decision-making of supply chain risk management has not been done yet. This paper describes a mechanism for pricing of agricultural commodities using a stakeholder dialogue approach to achieve the resolution of conflicts of interest based on balancing the risk of AP-SCM using fuzzy utility risk optimization. Fuzzy logic approach is used to measure and evaluate risk at every stages of supply chain with the input preferences or utility function of every supply chain actors in dealing with the risk of certain price changes [6]. Fuzzy non linear regression is used to estimate the value of risk utility of supply chain for each participant in dealing the price changes. With this mechanism all levels of the supply chain will be modeled by using an exponential fuzzy utility function with price as independent variable and the level of risk utility as dependent variable. Conflict resolution is done by making conjoint function between farmers' level of fuzzy utility functions with other levels of the utility function of the supply chain. Fuzzy utility function of each level of the supply chain will be approximated by using fuzzy linear regression [2]. The results of conjoint function will be searched to find a solution for settlement price of the deal. The solution of conjoint functions performed by linear interpolation with a range of values between the highest price and lowest price obtained from price quotes in the stakeholders dialogue of supply chain actors.

\section{Supply Chain Risk Balancing Model}

Supply chain risk balancing model is used to determine the corn price at farmer stage by considering the risks of each supply chain stage by using stakeholder dialog approach to get a concensus. This model consists of four sub-models: the model identifying risk factors for each level of supply chain, the price prediction model, and the model of risk balancing by using stakeholder dialogue and prices consensus model by using linear interpolation.

Supply chain risk identification model aims to identify and determine the risk variables and risk factors that are very influential on every stages of the supply chain. By using this model will be obtained the priority of risk factors from each level of AP-SCM along with the risk variables so that each level of the supply chain will focus on some selected risk factors in carrying out supply chain risk management. This model using fuzzy AHP (Analytical Hierarchy Process) to determine the weight of each risk factor and the selection of risk factor priority assessment based on expert input preferences.

Price prediction model at farm level using price data of corn in the last two years. This model used time series methods developed by holt winter for estimating the price of corn. 
Outputs of this model are used as inputs in models of risk balancing stakeholder dialogue to develop a nonlinear fuzzy regression function.

Stakeholder dialogue model is a model that is used to make a price negotiation of corn at farm level with the input utility value of risk factors at each level of supply chain based on the scenario of price exchanges. Therefore, the inputs of sub model are risk factors at every level of the agricultutal products supply chain (AP-SC), the desirable price of corn at all levels of AP-SC and the utility value of risk factors from each level of the AP-SC. Output from this sub model is the price of corn at farm level in accordance with the agreement. Price agreement is obtained automatically by interpolating against conjoint function of fuzzy non-linear regression functions at the level of farmers with fuzzy nonlinear regression functions at another level of the AP-SC.

The risk balancing model of AP-SC in order to get a deal priced at the level of farmers using the assumption that the risk at farm level tends to rise when prices decline and will tend to decrease if the price increase occurs. However, in the other parties in the AP-SC network, such as agro-industry, and collectors will have the risk that tends to decline if the price of raw materials will decrease and the risk tends to rise if the price of raw materials increases.

\section{a. Supply Chain Risk Identification}

Before conducting fuzzy risk analysis, one must identify the factors and sources of risks associated with AP-SCM. However, little empirical study has focused on identifying the potential risk factors that threaten each stage of agriculture supply chain. Initial study has been used for categorizing risk of AP-SC stages based on its source: environmental risks, demand risks, supply risks and internal risks [21]. Then the potential risks associated with agriculture supply chain was identified based on a comprehensive literature review and in-depth interviews with some experts (academics: a professor of supply chain management, researchers: Post-Harvest Agricultural Research Institutes, practitioners: Division chief procurement of raw material feed industry in Indonesia). The identified of agriculture supply chain risk factors could be classified into 12 risk categories as follow:

a) Environmental risks, caused by natural disasters, pests and diseases, public policy, security, socio-cultural and political conditions, competitors' products.

b) Risks of technology, sourced from the low mastery of technology, development of new technology and the availability of technology.

c) Price risk, which is caused by the inflation, exchange rates and interest rates, low product quality and quantity of supply.

d) The risks of supply are sourced from a diversity of quality of supply, supplier loyalty, and availability of supply.

e) The risks of transport caused by the choice of mode of transport, the uncertainty of time of transport, safety on the roads, and damage to roads to reduce product quality.

f) Market risks are sourced from market structure, price fluctuations, consumer rejection and standardization of quality in the market.

g) The risks of production caused by production capacity, production processes, use of production technology and quality raw materials.

h) The risks of information that originates from the use of forecasting methods, distortion of information and the use of methods of information transfer.

i) The risks of quality caused by the season, transportation methods, storage, supply of quality variation, and production processes.

j) The risks of storage caused by the uncertainty of supply, demand uncertainty, depreciation and deterioration as well as geographic location.

k) The risks of partnership that comes from choosing a partner, loss of communication networks, transportation networks and the loss of partner commitment. 
1) Internal risks, caused by capacity, production, storage, transportation mode and planning.

To be able to identify the risks at each stage of AP-SCM is carried out by using Fuzzy Analytical Hierarchy Process (fuzzy-AHP) [14]. So it will be obtained risk factors of each stage along the AP-SC associated with thier risk variables. The hierarchical structure of AHP analysis process can be seen at Figure 3. Then the structure of this hierarchy will be judged by some experts to obtain prime factors of each level of the AP-SC. In this case four factors will be selected with the highest weighting of each stage on the AP-SC as the dominant risk factors. These dominant factors will be used as a constraint input of stakeholder dialoge for price negotiation on AP-SCM.

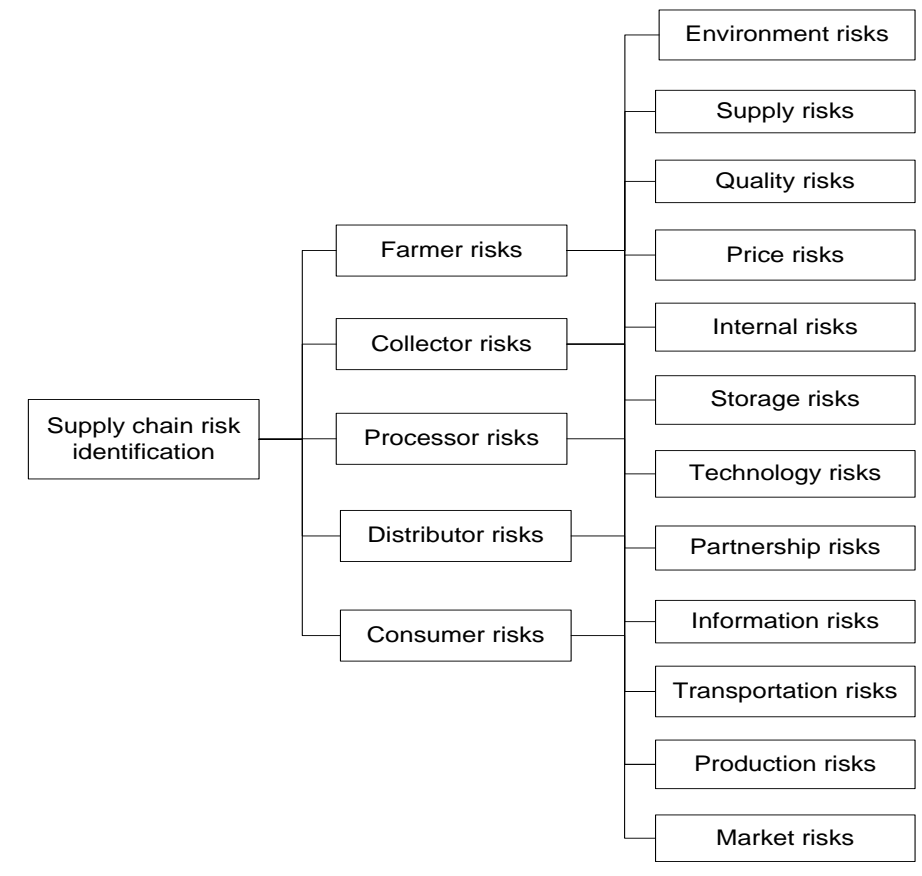

Figure 3. AP-SC Risk Identification Structure

\section{b. Fuzzy Risk Utility Function for Each Stage of AP-SCM}

The method used in the risk balancing of AP-SCM is stakeholder dialogue among the parties concerned in the supply chain risk management in order to obtain the consensus value in the balancing of risk because of conflicts of interests in the determination of prices at farm level. Consensus is done by assessing the value of risk utility for each level of supply chain based on corn price exchange at the farmer level. This process will be modeled using fuzzy nonlinear regression for risk utility function of each level of supply chain with the price exchange at the farm level as independent variables.

Fuzzy regression function was used in this model, because the utility value of risk as the dependent variable and the value of price exchanges as the independent variable are fuzzy number. The utility value of each risk factor was assessed by risk probability and risk impact in fuzzy number. The membership function of fuzzy number for for each risk factor was represented using Triangular Fuzzy Number (TFN).

Linguistic fuzzy number of the risk probability has values of None $(\mathrm{N})$ with a range of values [1, 1, 2], Very Low (VL) with a range of values [1, 2, 3], Low (L) with a range of values [2, 3, 4], Moderately Low (ML) with a range of values [3, 4:25, 5.5], Moderate (M) with a range of values [4, 5.5, 7], Moderately High (MH) with a range of values [5.5, $6.75,8]$, High $(\mathrm{H})$ with a range of values $[7,8,9]$, Very High $(\mathrm{VH})$ with a range of values $[8,9,10]$, and the Almost certainty $(\mathrm{AC})$ with a range of values $[9,10,10]$. The 
representation of the membership function TFN (Triangular Fuzzy Number) of the probability of risk can be explained by Figure 4.

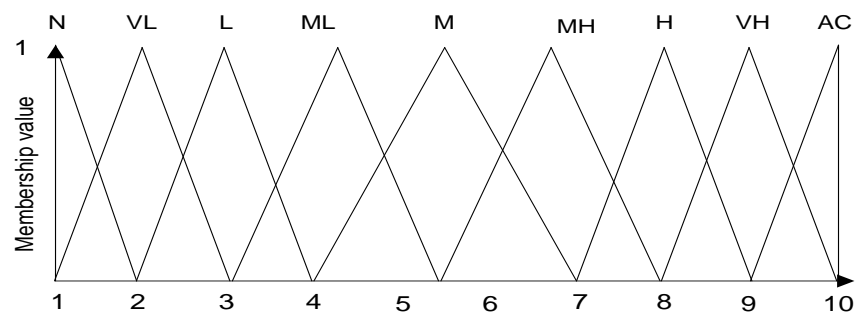

Figure 4. Fuzzy Representations of Risk Probability and Risk Impact

Risk utility function of each stage of AP-SCM can be represented as a non-linear regression function as follow:

$$
U_{k}(x)=\alpha e^{\beta(x)}
$$

Where $\mathrm{U}_{\mathrm{k}}(\mathrm{x})$ is the risk utility function at $\mathrm{k}$ level of a AP-SC network and $\mathrm{x}$ is the price of corn at the farmer level.

Since each level of the supply chain has several risk factors, the risk utility function for each actor of AP-SC can be obtained from the aggregation of risk factors for each level of the supply chain by using the weighted mean as follows:

$$
\begin{gathered}
U_{k}(x)=\sum_{i=1}^{n} w_{i} R_{i k}(x) \\
\sum_{i=1}^{n} w_{i}=1
\end{gathered}
$$

Where $R_{i k}(x)$ is the utility value of $i$ risk factors at $k$ level of supply chain. And $w_{i}$ is the weighting of each risk factor obtained from the analysis using the analytic hierarchy process.

The Utility value of risk factors can be obtained from the utility value of risk variables for each factor of AP-SC using geometric mean as follow:

$$
R_{i k}(x)=\sqrt[m]{\prod_{j=1}^{m} V_{j i k}(x)}
$$

Where $\mathrm{V}_{\mathrm{jik}}(\mathrm{x})$ is the utility value of risk variable $\mathrm{j}$ on i risk factors for $\mathrm{k}$ levels of supply chain at price $x$. The utility values of risk variables was obtained by multiplying the value of risk probability and risk impact of these variables, with the following formula:

$$
V_{i j k}(x)=P_{i j k}(x) S_{i j k}(x)
$$

Where $P_{\mathrm{ijk}}(\mathrm{X})$ is the probability of risks and $\mathrm{S}_{\mathrm{ijk}}(\mathrm{x})$ is the risk impact of $\mathrm{i}$ risk variables on $\mathrm{j}$ risk factors and $\mathrm{k}$ level supply chain. The value of risk impact and probability of this risk is measured by fuzzy numbers based on an assessment by the stakeholders in the supply chain to assess levels of risk based on a price exchange of corn at farmer level.

Linguistics fuzzy number of price exchanges has values of Very High Decrease (VHD) with a range of values [50\%, 50\%, 60\%], High Decrease (HD) with a range of values [50\%, 60\%, 70\%], Moderate Decrease (MD) with a range of values [60\%, 70\%, 80\%], Low Decrease (LD) with a range of values [70\%, 80\%, 90\%], Very Low Decrease (VLD) with a range of values $[80 \%, 90 \%, 100 \%]$, Normal $(\mathrm{N})$ with a range of values [90\%, $100 \%, 110 \%]$, Very Low Increase (VLI) with a range of values [100\%, 110\%, 120\%], 
Low Increase (LI) with a range of values [ $110 \%, 120 \%, 130 \%]$, Moderate Increase (MI) with a range of values [120\%, 130\%, 140\%], High Increase (HI) with a range of values $[120 \%, 130 \%, 140 \%]$, and High Increase (HI) with a range of values [130\%, 140\%, $150 \%$ ]. The membership function of maize price exchanges at farm level can be represented by using TFN (Triangular Fuzzy Number) on Figure 6.

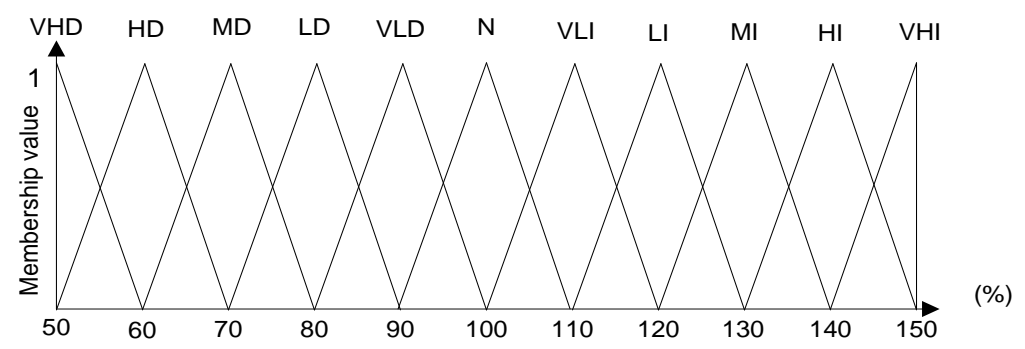

Figure 6. Fuzzy Representations of Corn Price Exchanges Values at Farm

\section{Level}

Based on the equation (2), (3) and (5) will be obtained the fuzzy risk utility function as follows:

$$
U_{k}(x)=\sum_{i=1}^{n} w_{i}\left(\sqrt[m]{\prod_{j=1}^{m} P_{i j k}(x) S_{i j k}(x)}\right)
$$

By substituting equation (6) into equation (1), it will get the following equation:

$$
\sum_{i=1}^{n} w_{i}\left(\sqrt[m]{\prod_{j=1}^{m} P_{i j k}(x) S_{i j k}(x)}\right)=\alpha e^{\beta(x)}
$$

This equation is a function of fuzzy non-linear regression, to obtain the solution of this equation should be converted to fuzzy linear regression equation as follows:

$$
\mathrm{Y}=\mathrm{B}_{0}+\mathrm{B}_{1} \mathrm{X}
$$

Where:

$$
\begin{aligned}
& Y=\ln \left(\sum_{i=1}^{n} w_{i}\left(\sqrt[m]{\prod_{j=1}^{m} P_{i j k}(x) S_{i j k}(x)}\right)\right) \\
& B_{0}=\ln (\alpha) \\
& B_{1}=\beta
\end{aligned}
$$

$\mathrm{X}=\mathrm{x} * \mathrm{P}$, where $\mathrm{P}$ is the price prediction using time series method. Equation (8) can be solved by using methods developed by [2], to obtain the value of $B_{o}$ and $B_{1}$ as follow:

$$
\begin{array}{r}
\hat{B}_{1}^{+}=\frac{S S_{x y}^{+}}{S S_{x x}} \\
\hat{B}_{0}^{+}=\tilde{Y}-\hat{B}_{1}^{+} \tilde{X}
\end{array}
$$

Where: 


$$
\begin{aligned}
& \tilde{X}=\int_{0}^{1} \frac{\bar{X}^{L}(\alpha)+\bar{X}^{U}(\alpha)}{2} d \alpha \\
& \tilde{Y}=\int_{0}^{1} \frac{\bar{Y}^{L}(\alpha)+\bar{Y}^{U}(\alpha)}{2} d \alpha \\
& S S_{x x}=\sum_{i=1}^{n} \int_{0}^{1}\left(\left(X_{i}^{L}(\alpha)\right)^{2}+\left(X_{i}^{U}(\alpha)\right)^{2}\right) d \alpha-2 n \tilde{X}^{2} \\
& S S_{x y}^{+}=\sum_{i=1}^{n} \int_{0}^{1}\left(X_{i}{ }^{L}(\alpha) Y_{i}{ }^{L}(\alpha)+X_{i}^{U}(\alpha) Y_{i}^{U}(\alpha)\right) d \alpha-2 n \tilde{X} \tilde{Y}
\end{aligned}
$$

In the same way, then the fuzzy risk utility function can be obtained on the other level supply chain, for example at the level of collector, agro-industry level, the level of the distributor and consumer level of AP-SCM.

\section{c. Stakeholder Dialoge for Price Negotiation based on AP-SC Risk Balancing}

The risk balancing of supply chain is done by determining the risk utility function of each level of using fuzzy price exchange scenarios as described in Figure 6, it will be got a risk utility function for each level in the supply chain, such as equation (1). This process is done by creating a conjoint function of each utility function of risk in order to obtain the following equation:

$$
H(x)=U_{p}(x)-\sum_{k=1}^{n} Q_{k} U_{k}(x)
$$

Where $\mathrm{H}(\mathrm{x})$ is the conjoint utility function of risk for price negotiations of AP-SCM, $U_{p}(x)$ is the utility function of risk at farm level, $U_{k}(x)$ is the utility function of risk on another level and $\mathrm{Q}_{\mathrm{k}}$ is the weight of the supply chain level obtained from the analysis using analytic hierarchy process.

The Value $\mathrm{x}$ of the function above can be found by searching the minimum value of function $\mathrm{H}(\mathrm{x})$ based on linear regression equations to obtain the value of $\alpha$ and $\beta$.

The solution of the equation (18) above can be done by linear programming or linear interpolation to minimize $\mathrm{H}(\mathrm{x})$ as follows:

$$
H(x)=\alpha_{p} e^{\beta_{p}(x)}-\sum_{k=1}^{n} Q_{k} \alpha_{k} e^{\beta_{k}(x)}
$$

With constraints:

$$
\begin{gathered}
\mathrm{X}_{0}<\mathrm{x}<\mathrm{X} 1 . \\
\sum_{k=1}^{n} Q_{k}=1
\end{gathered}
$$

Where $\mathrm{X}_{0}$ is the lowest offer price and the $\mathrm{X}_{1}$ is the highest bid price in a price negotiation using the stakeholder dialogue.

Stakeholder dialogue steps can be explained in the Figure 7. The first step is to incorporate actors involved in negotiating the price with the stakeholder dialogue. Then, from each stakeholder inputs risk factors that have been previously identified by using four dominant risk factors along with their variables. Then it was determined the fuzzy membership function of risk variables and risk factors for each level of the AP-SC, and the fuzzy membership function of corn price exchanges at farm level. For each exchange price, assess the risk variables by inputing the risk impact and probability of risk. The risk Utility values of variables is obtained by multiplying the value of impact and probability value. Then by using current corn prices and desirable corn prices at every level of supply 
chain and using equation (19) with linear interpolation will be obtained the value of the deal price at farm level.

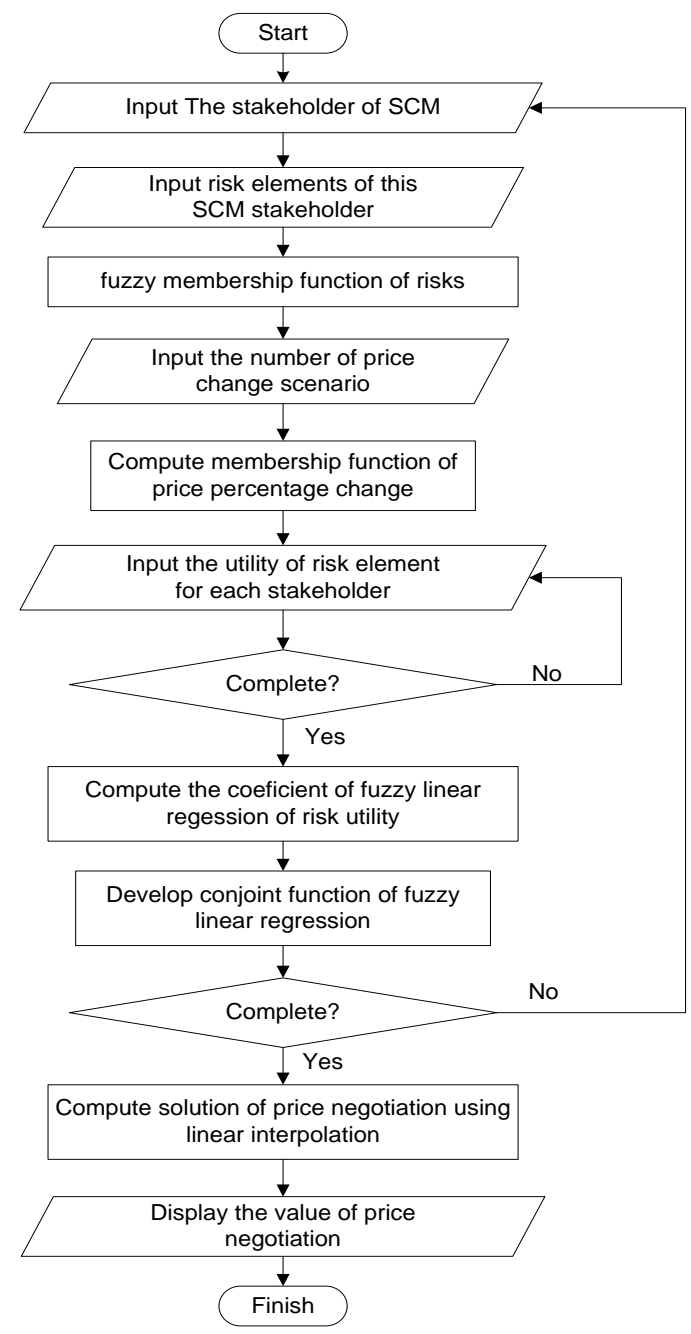

Figure 7. Flowchart of AP-SC Risk Balancing Model

\section{Application Example and Discussion}

In this section will be described examples of the implementation of supply chain risk balancing models using stakeholder dialogue in determining the price at farm level with the criterion of risk faced by each stakeholder. The results of the risk identification at every level of the AP-SC can be described in a hierarchy structure as shown in Figure 8.

By using the utility values of those risks and the input current price by IDR.3000/Kg then a fuzzy linear regression analysis can be obtained from the risk utility function of each level of supply chain.

The fuzzy risk utility function at farm level of AP-SCM can be represented as follow:

$$
U_{F}(x)=18.23549 e^{-0.000383 x}
$$

By using the same procedure the fuzzy risk utility function at collector level of APSCM can be represented as follow:

$$
U_{C o l}(x)=0.940473 e^{0.000545 \mathrm{X}}
$$


The fuzzy risk utility function at processor level of AP-SCM can be represented as follow:

$$
U_{P}(x)=1.192086 e^{0.000489 \mathrm{X}}
$$

The fuzzy risk utility function at distributor level of AP-SCM can be represented as follow:

$$
U_{D}(x)=0.794616 e^{0.000590 \mathrm{X}}
$$

And the fuzzy risk utility function at consumer level of AP-SCM can be represented as follow:

$$
U_{C u s}(x)=0.725807 e^{0.000624 \mathrm{X}}
$$

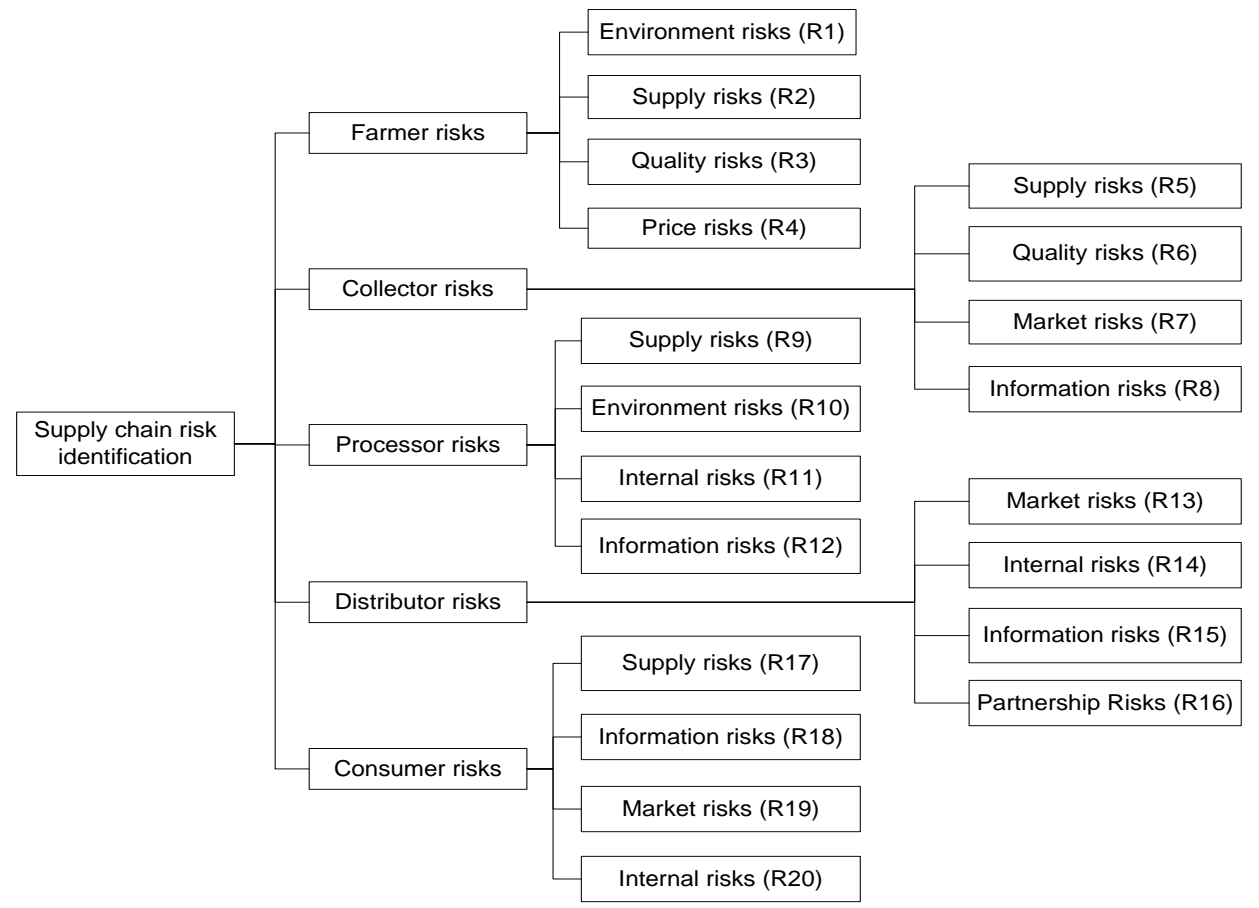

Figure 8. The Structure of Identified Risks on AP-SCM

Price negotiation can be done bilaterally or multilaterally between each level of the supply chain of agricultural products. As an example of a conjoint function of the risks utility function with equal weight to each level of the supply chain for multilateral negotiating prices can be represented by the following equation:

$H(X)=18.23549 e^{-0.000383 x}-\left(0.940473 e^{0.000545 X}+_{1.192086} e^{0.000489 \mathrm{X}} \boldsymbol{+}_{0.794616} e^{0.000590 \mathrm{X}} \boldsymbol{+}_{0.725807} e^{0.000624 \mathrm{X}}\right) / 4$

Therefore, by using linear interpolation with the initial input value $\mathrm{x}$ is the value of the highest bid price for IDR.3500/Kg and the lowest bid price of IDR.2700/Kg, it will get the negotiated price for IDR.3187/Kg (note: 1US \$ = IDR.9200,-).

Conjoint function for price negotiates bilaterally between farmers and the processors can be represented as follows:

$$
H(X)=18.23549 e^{-0.000383 \quad X}-0.940473 e^{0.000545 X}
$$


From the identified risks are then carried out risk assessment by each stakeholder. The utility value of risk of each stakeholder can be shown by Table 2 .

Tabel 2. Fuzzy Utility Value of Each AP-SC Stage

\begin{tabular}{|c|c|c|c|c|c|c|c|c|c|c|c|c|c|c|c|c|c|c|c|c|}
\hline \multirow{2}{*}{$\begin{array}{c}\text { Price } \\
\text { change }\end{array}$} & \multicolumn{4}{|c|}{ Farmer Risk } & \multicolumn{4}{|c|}{ Collectors Risk } & \multicolumn{4}{|c|}{ Processor Risk } & \multicolumn{4}{|c|}{ Distributor Risk } & \multicolumn{4}{|c|}{ Consumer Risk } \\
\hline & R1 & R2 & R3 & R4 & R5 & R6 & R7 & R8 & R9 & R10 & R11 & R12 & R13 & R14 & R15 & R16 & R17 & R18 & R19 & R20 \\
\hline VHD & $A C$ & $A C$ & $A C$ & $A C$ & L & VL & VL & VL & VL & L & VL & L & VL & VL & VL & VL & VL & VL & VL & VL \\
\hline HD & $A C$ & $\mathrm{VH}$ & $A C$ & $\mathrm{VH}$ & $\mathrm{L}$ & L & $\mathrm{L}$ & VL & L & $\mathrm{L}$ & L & $\mathrm{L}$ & VL & $\mathrm{L}$ & L & VL & $\mathrm{L}$ & VL & VL & L \\
\hline MD & $\mathrm{VH}$ & $\mathrm{VH}$ & $\mathrm{VH}$ & $\mathrm{VH}$ & $\mathrm{ML}$ & $\mathrm{ML}$ & $\mathrm{L}$ & L & $\mathrm{ML}$ & $\mathrm{ML}$ & $\mathrm{ML}$ & $\mathrm{ML}$ & $\mathrm{L}$ & $\mathrm{L}$ & ML & $\mathrm{L}$ & $\mathrm{L}$ & $\mathrm{L}$ & $\mathrm{L}$ & $\mathrm{L}$ \\
\hline LD & VH & H & $\mathrm{VH}$ & H & $\mathrm{ML}$ & $M L$ & $\mathrm{ML}$ & L & $\mathrm{ML}$ & $\mathrm{ML}$ & $\mathrm{ML}$ & ML & $\mathrm{ML}$ & $\mathrm{ML}$ & $\mathrm{ML}$ & $\mathrm{L}$ & $\mathrm{ML}$ & $\mathrm{L}$ & $\mathrm{ML}$ & ML \\
\hline VLD & $\mathrm{H}$ & $\mathrm{H}$ & $\mathrm{H}$ & $\mathrm{MH}$ & M & M & ML & $M L$ & M & M & M & M & M & $\mathrm{ML}$ & M & $\mathrm{ML}$ & $\mathrm{ML}$ & $\mathrm{ML}$ & $\mathrm{ML}$ & ML \\
\hline $\mathrm{N}$ & $\mathrm{MH}$ & $\mathrm{MH}$ & $\mathrm{MH}$ & M & M & $\mathrm{MH}$ & M & $\mathrm{ML}$ & M & M & IVI & M & M & M & M & M & M & M & M & M \\
\hline VLI & $\mathrm{MH}$ & $\mathrm{MH}$ & M & M & $\mathrm{MH}$ & $\mathrm{MH}$ & M & M & $\mathrm{MH}$ & $\mathrm{MH}$ & $\mathrm{MH}$ & M & M & $\mathrm{M}$ & $\mathrm{MH}$ & M & M & $\mathrm{MH}$ & $\mathrm{MH}$ & $\mathrm{MH}$ \\
\hline LI & M & $M$ & $\mathrm{ML}$ & $\mathrm{ML}$ & $\mathrm{MH}$ & $\mathrm{H}$ & $\mathrm{MH}$ & $\mathrm{MH}$ & $\mathrm{MH}$ & $\mathrm{MH}$ & $\mathrm{MH}$ & $\mathrm{MH}$ & $\mathrm{MH}$ & $\mathrm{MH}$ & $\mathrm{MH}$ & $\mathrm{MH}$ & $\mathrm{MH}$ & $\mathrm{H}$ & $\mathrm{H}$ & $\mathrm{MH}$ \\
\hline MI & $\mathrm{ML}$ & $\mathrm{ML}$ & $\mathrm{ML}$ & $\mathrm{ML}$ & $\mathrm{H}$ & $\mathrm{H}$ & $\mathrm{MH}$ & $\mathrm{MH}$ & $\mathrm{H}$ & $\mathrm{H}$ & $\mathrm{H}$ & $\mathrm{H}$ & $\mathrm{H}$ & $\mathrm{MH}$ & $\mathrm{H}$ & $\mathrm{H}$ & $\mathrm{H}$ & $\mathrm{H}$ & $\mathrm{H}$ & $\mathrm{H}$ \\
\hline $\mathrm{HI}$ & $\mathrm{ML}$ & $\mathrm{L}$ & $\mathrm{L}$ & $\mathrm{L}$ & $\mathrm{H}$ & $\mathrm{VH}$ & $\mathrm{H}$ & $\mathrm{H}$ & $\mathrm{H}$ & $\mathrm{H}$ & $\mathrm{VH}$ & $\mathrm{H}$ & $\mathrm{VH}$ & $\mathrm{H}$ & $\mathrm{H}$ & $\mathrm{VH}$ & $\mathrm{VH}$ & $\mathrm{VH}$ & $\mathrm{VH}$ & $\mathrm{VH}$ \\
\hline VHI & $\mathrm{L}$ & $\mathrm{L}$ & $\mathrm{VL}$ & $\mathrm{VL}$ & $\mathrm{VH}$ & $\mathrm{AC}$ & $\mathrm{VH}$ & $\mathrm{VH}$ & $\mathrm{VH}$ & $\mathrm{VH}$ & $\mathrm{VH}$ & $\mathrm{VH}$ & $\mathrm{VH}$ & $\mathrm{VH}$ & $\mathrm{VH}$ & $\mathrm{VH}$ & $A C$ & $A C$ & $\mathrm{VH}$ & $\mathrm{VH}$ \\
\hline
\end{tabular}

Therefore, by using linear interpolation with the highest bidding price of inputs for IDR.3000/Kg and the lowest offer price for IDR.2000/Kg will get the price agreement between the two sides of IDR.3128/Kg.

The result of price negotiations with the consideration of the risk balancing of supply chain is greater than the initial price forecast, it means that this concept has shown a shift of risk from the farmer to the other parties in the supply chain in accordance with the balance of risk constraints.

\section{Conclusion}

This paper has described the use of fuzzy non linear regression as a tool to obtain constant values of the risk utility function of each stage of AP-SCM in order to negotiate a price of corn at farmer stage of supply chain network based on the risks constraint of each stakeholder by using stakeholder dialogue approach to balance their risks. Pricing negotiation on this approach can determine a fair price negotiation using risks utility preference of each stakeholder in AP-SCM.

Stakeholder dialogue on risk management of agricultural product supply chain can be done bilaterally or multilaterally to balance the supply chain risks by using risk utility function of each level of the supply chain. The utility function of risk at farm level tends to fall if the price of corn rises, the opposite risk utility function at the level of agroindustries tend to increase if the price of raw materials rises, so it can be formed a conjoint function between both of the risk utility function to get a point of mutual agreement.

The contribution of this research generally can be classified into two things: the first thing is the development of supply chain risks balancing mechanism for price negotiation using stakeholder dialogue. The second is risk identification has been carried out for each stage of the AP-SCM based on tweleve risk factors to find four dominant risk factors.

These supply chain risk balancing research can be continued to create a stakeholder dialogue negotiation model with multiple objectives such as improving the quality, profit sharing, fair pricing and value added distribution by using a multiatributes fuzzy regression as estimators of utility functions for each decision maker on AP-SCM. 


\section{References}

[1] F. J. Andre and L. Riesgo, "A non-interactive elicitation method for non-linear multiattribute utility functions: Theory and application to agricultural economics", European Journal of Operational Research, (2007), pp. 793-807.

[2] A. Bargiela, W. Pedrycz, and T. Nakashima, "Multiple regression with fuzzy data", Fuzzy Sets and Systems, (2007), pp. $2169-2188$.

[3] C. B. Cheng, C. C. H. Chan, and K. C. Lin, "Intelligent agents for e-marketplace: Negotiation with issue trade-offs by fuzzy inference systems", Decision Support Systems, (2006), pp. 626-638.

[4] S. Chopra and M. S. Sodhi, "Managing risk to avoid supply chain breakdown", MIT Sloan Management Review, (2004).

[5] E. Cuppen, S. Breukers, M. Hisschemöller, and E. Bergsma, "Analysis Q methodology to select participants for a stakeholder dialogue on energy options from biomass in the Netherlands", Ecological Economics, (2010), pp. 579-591.

[6] M. Ding, W. T. Ross Jr., and V. R. Rao, "Price as an indicator of quality: Implications for utility and demand functions", Journal of Retailing, (2010), pp. 69-84.

[7] A. Grassi, R. Gamberini, C. Mora, and B. Rimini, "A fuzzy multi-attribute model for risk evaluation in workplaces", Safety Science, vol. 47, (2009), pp. 707-716.

[8] J. Hallikas, I. Karvonen, U. Pulkkinen, and V. M. Virolainen, "Risk management processes in supplier networks", Int. Journal Production Economics, (2004), pp. 47-58.

[9] C. Harland, R. Brenchley, and H. Walker, "Risk in supply networks", Journal of Purchasing \& Supply Management, (2003), pp. 51-62.

[10] E. Herrera-Viedma, S. Alonso, F. Chiclana, and F. Herrera, "A consensus model for group decision making with incomplete fuzzy preference relations", IEEE Transactions On Fuzzy Systems, (2007), pp. 863-877.

[11] V. Jain and S. G. Deshmukh, "Dynamic supply chain modeling using a new fuzzy hybrid negotiation mechanism", Int. Journal Production Economics, vol. 122, (2009), pp. 319-328.

[12] P. Moeinzadeh and A. Hajfathaliha, "A combined fuzzy decision making approach to supply chain risk assessment", World Academy of Science, Engineering and Technology, (2009), pp. 519-535.

[13] Y. Moon, T. Yao, and S. Park, "Price negotiation under uncertainty", Int. Journal Production Economics, 2009, doi:10.1016/j.ijpe.2009.11.019.

[14] B. Nepal, O. P. Yadav, and A. Murat, "A fuzzy-AHP approach to prioritization of CS attributes in target planning for automotive product development", Expert Systems with Applications, (2010), doi:10.1016/j.eswa.2010.03.048.

[15] A. Oke and M. Gopalakrishnan, "Managing disruptions in supply chains: A case study of a retail", Int. Journal Production Economics, (2009), pp. 168-174.

[16] H. Peck, "Drivers of supply chain vulnerability: An integrated framework", Int. Journal of Physical Distribution and Logistics Management, (2005), pp. 210-232.

[17] H. Rau, T. F. Chen, and C. W. Chen, "Develop a negotiation framework for automating B2B processes in the RosettaNet environment using fuzzy technology", Computers \& Industrial Engineering, vol. 56, (2009), pp. 736-753.

[18] H. M. Regan, M. Colyvan, and L. Markovchick-Nicholls, "A formal model for consensus and negotiation in environmental management", Journal of Environmental Management, vol. 80, (2006), pp. $167-176$.

[19] T. Schoenherr, V. M. R. Tummala, and T. P. Harrison, "Assessing supply chain risks with the analytic hierarchy process: Providing decision support for the offshoring decision by a US manufacturing company", Journal of Purchasing \& Supply Management, (2008), doi:10.1016/j.pursup.2008.01.008.

[20] R. E. Spekman and E. W. Davis, "Risky business: Expanding the risk and the extended enterprise", Int. Journal of Physical Distribution and Logistics management, (2004), pp. 414-433.

[21] Suharjito and Marimin, "The evaluation model of the risks in each supply chain stage of the agricultural food crop products", Int. Seminar on Industrial Engineering and Management, Bali, (2009), pp. B46B53.

[22] H. Tamura, "Modeling ethical conflict resolution for planning a safe, secure and reliable (SSR) megacity", http://www.iiasa.ac.at/Research/RMS/dpri2002/Papers/Tamura.pdf.

[23] C. Tang and B. Tomlin, "The power of flexibility for mitigating supply chain risks", Int. Journal Production Economics, (2008), pp. 12-27.

[24] Vanany, S. Zailani, and N. Pujawan, "Supply chain risk management: literature review and future research", Int. Journal of Information Systems and Supply Chain Management, (2009), pp. 16-33.

[25] M. Welp, A. Vega-Leinert, S. Stoll-Kleemann, and C. C. Jaeger, "Science-based stakeholder dialogues: Theories and tools", Global Environmental Change, vol. 16, (2006), pp. 170-181.

[26] J. Wilkes, :Utility fuctions, prices, and negotiation”, in: Market Oriented Grid and Utility Computing, edited by R. Buyya and K. Bubendorfer, John Wiley \& Sons, Inc., (2008).

[27] T. Wu, J. Blackhurst, and V. Chidambaram, "A model for inbound supply risk analysis", Computers in Industry, vol. 57, (2006), pp. 350-365. 
[28] W. Xiaohui, Z. Xiaobing, S. Shiji, and W. Cheng, "Study on risk analysis of supply chain enterprises", Journal of Systems Engineering and Electronics, (2006), pp. 781-787.

[29] J. Yang, and W. Qiu, "A measure of risk and a decision-making model based on expected utility and entropy", European Journal of Operational Research, vol. 164, (2005), pp. 792-799.

[30] Y. N. Yang and C. C. Chiang, "Risk-sharing aspects of supply chain coordination with revenue-sharing contracts", Int. Conference on Enterprise Systems, Accounting and Logistics, Crete, Greece, (2009). 
International Journal of Hybrid Information Technology

Vol.8, No.1 (2015) 